\title{
JGZ-richtlijn Hartafwijkingen
}

\author{
J. A. Deurloo $\cdot$ N. Heerdink
}

Published online: 10 July 2017

(c) Bohn Stafleu van Loghum 2017

Samenvatting In januari 2017 is de jeugdgezondheidszorg (JGZ) Richtlijn Hartafwijkingen gepubliceerd. Deze richtlijn is een herziening van de in 2005 gepubliceerde JGZ-richtlijn Vroegtijdige opsporing van aangeboren hartafwijkingen. Een belangrijk doel van de herziene richtlijn is om JGZ-professionals te ondersteunen bij de vroegtijdige opsporing van (aangeboren \& verworven) hartafwijkingen en de preventie van hart- en vaatziekten.

Trefwoorden hartafwijkingen - hart- en vaatziekten • jeugdgezondheidszorg

\section{Waarom deze richtlijn?}

In Nederland worden ongeveer 1.250 kinderen per jaar geboren met een hartafwijking [1]. Sinds 2007 wordt door middel van prenatale echografie op aangeboren hart- en vaatafwijkingen gescreend, hiermee wordt $40-50 \%$ van de hartafwijkingen ontdekt [2]. Het opsporen van aangeboren hartafwijkingen is een wettelijke taak van de JGZ. Door tijdig opsporen van harten/of vaatziekten (HVZ) beoogt men te voorkomen dat irreversibele vaatschade ontstaat, met ernstige morbiditeit of mortaliteit als gevolg. HVZ zijn wereldwijd de belangrijkste doodsoorzaak [3]. HVZ worden vaak veroorzaakt door atherosclerose, dit proces begint al op jonge leeftijd [4]. Voor de preventie van HVZ is het van belang dat de JGZ al vanaf jonge leeftijd aandacht heeft voor de risicofactoren voor HVZ.

J. A. Deurloo $(\square) \cdot$ N. Heerdink

TNO Child Health, Leiden, Nederland

jacqueline.deurloo@tno.nl

J. A. Deurloo

GGD Hollands Noorden, Alkmaar, Nederland

\section{Uitgangsvragen}

Naar aanleiding van de knelpuntenanalyse is het onderwerp van de herziene JGZ-richtlijn Hartafwijkingen [5] uitgebreid. De knelpunten zijn vertaald naar de volgende uitgangsvragen, waarop in de nieuwe richtlijn een antwoord wordt gegeven.

1. Wat zijn nieuwe inzichten in preventie, diagnostiek en behandeling van hartafwijkingen sinds de huidige richtlijn?

2. Wat is de maximale termijn waarbinnen de JGZ een kind na geboorte moet zien om hartafwijkingen te signaleren?

3. Wanneer (frequentie en leeftijd) moet de JGZ kinderen minimaal zien om hartafwijkingen te kunnen signaleren?

4. Wat is de toegevoegde waarde van de zuurstofsaturatiemeting binnen de JGZ en hoe kunnen JGZprofessionals deze uitvoeren?

5. Hoe kunnen jeugdartsen eenvoudig nader onderzoek uitvoeren bij een gesignaleerd hartgeruis?

6. Wat moeten jeugdartsen minimaal doen als zij een geruis horen, en wanneer moeten zij verwijzen, wat moet de jeugdarts weten over endocarditisprofylaxe en voelen van de aa. femorales?

7. Hoe kunnen JGZ-professionals coarctatio aortae diagnosticeren als het voelen van de aa. radiales en/of aa. femorales niet lukt?

8. Op welke punten in de (voormalige) richtlijn kan het voelen van de arteria radialis worden vervangen door de arteria brachialis?

9. Wat is de uiterste termijn waarna moet worden verwezen bij het niet (goed) voelen van de aa. femorales?

10. Hoe kunnen JGZ-professionals, voor verschillende leeftijden, verworven hartafwijkingen signaleren? 
11. Wat zijn aritmieën (hartritmestoornissen), oorzaken hiervan en hoe kunnen JGZ-professionals deze signaleren?

12. Wat is de toegevoegde waarde van het bepalen van de kans op HVZ bij jongeren van 15 tot 16 jaar door de JGZ?

13. Wat is de toegevoegde waarde van de bloeddrukmeting binnen de JGZ en hoe kunnen JGZ-professionals deze uitvoeren?

14. Welke samenwerkingsafspraken moet de JGZ met welke andere partijen maken over signalering en/of beoordeling van hartafwijkingen?

15. Wat is het belang van kinderen zien zonder kleding en wat moeten JGZ-professionals hierbij verplicht registreren?

\section{Opbouw van de richtlijn en aanbevelingen}

De richtlijn geeft aanbevelingen voor het opsporen van aangeboren hartafwijkingen, specifiek in de eerste 6 levensmaanden. Daarnaast bevat de richtlijn informatie over de signalen van verworven hartafwijkingen, risicofactoren voor HVZ en de psychosociale gevolgen van (aangeboren) hartafwijkingen. Ten slotte beschrijft de richtlijn welke mogelijke (preventieve) interventies de JGZ kan bieden.

Onderzoeksmomenten. De richtlijn adviseert om kinderen in de eerste 14 maanden 5 keer te laten onderzoeken op aangeboren hartafwijkingen, waarvan minimaal 4 keer door de jeugdarts of verpleegkundig specialist. Belangrijke onderzoeksmomenten zijn het huisbezoek 14 dagen na de geboorte en het eerste

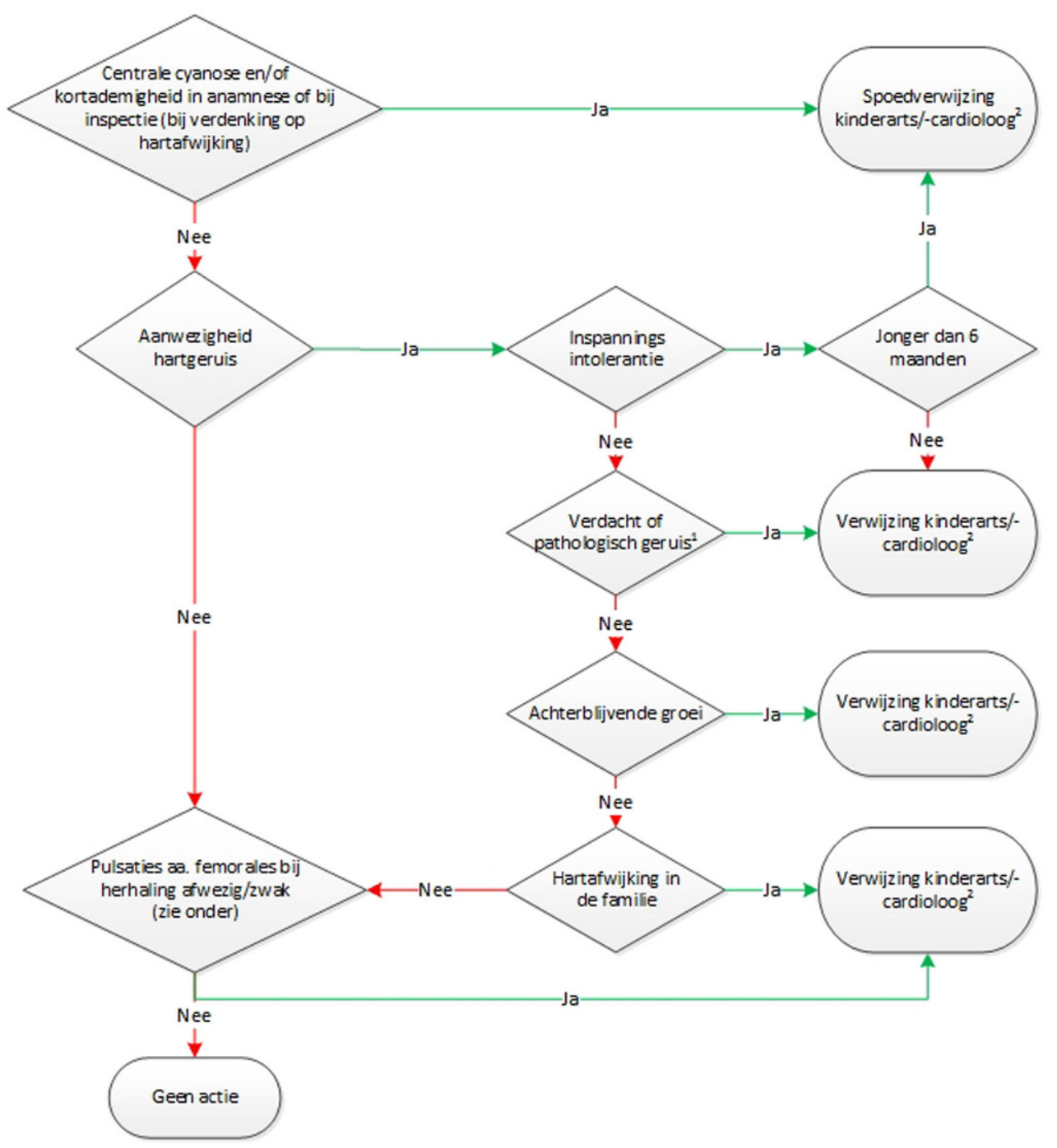

${ }^{1} \mathrm{Bij} \mathrm{twijfel} \mathrm{over} \mathrm{de} \mathrm{aard} \mathrm{van} \mathrm{het} \mathrm{hartgeruis,} \mathrm{wor} \mathrm{dt} \mathrm{bij} \mathrm{zuigelingen} \mathrm{een} \mathrm{vervolgafspraak} \mathrm{gemazkt} \mathrm{na} \mathrm{maximaal} \mathrm{vier} \mathrm{weken.} \mathrm{Bij} \mathrm{oudere} \mathrm{kinderen} \mathrm{kan}$
eventueel langer gewacht worden.
${ }^{2}$ Verwijzing geschiedt altijd met kennisgeving aan of na overleg met de huisarts

Figuur 1 Beslisschema verwijzen aangeboren hartafwijkingen 
contact bij de jeugdarts op 4 weken. De jeugdverpleegkundige dient bij het eerste huisbezoek de pasgeborene ontbloot te onderzoeken. Daarnaast wordt aanbevolen om jeugdigen die pas op latere leeftijd voor het eerst door de JGZ worden onderzocht (zogenaamde 'nieuwkomers') binnen 3 maanden door de jeugdarts te laten onderzoeken. (fig. 1)

Anamnese en lichamelijk onderzoek. Het onderzoek bestaat uit de volgende onderdelen: anamnese, monitoring groei, lichamelijk onderzoek (inspectie, palpatie en auscultatie). Bij jeugdigen $>5$ jaar met overgewicht wordt tevens de bloeddruk gemeten.

Coarctatio Aortae (CoAo). Belangrijke momenten voor de opsporing van CoAo zijn het huisbezoek 14 dagen na de geboorte, en de eerste twee contacten bij de jeugdarts. De jeugdarts palpeert de aa. femorales. Bij twijfel aan de (kwaliteit van) de pulsaties worden de femoralispulsaties vergeleken met de brachialispulsaties (en/of met de radialispulsaties) en wordt op de rug tussen de schouderbladen geausculteerd. Bij blijvende twijfel wordt verwezen naar kinderarts of kindercardioloog.

Aritmieën en verworven hartafwijkingen. Jeugdartsen en jeugdverpleegkundigen dienen op de hoogte zijn van de belangrijkste signalen van een aritmie of verworven hartafwijking. Bij klachten in combinatie met afwijkingen bij lichamelijk onderzoek en/of bij klachten in combinatie met een positieve familieanamnese voor aritmieën wordt de jeugdige verwezen naar de kindercardioloog.

Risico op hart- en vaatziekten. Jeugdartsen en jeugdverpleegkundigen dienen regelmatig aandacht te besteden aan de risicofactoren voor HVZ: voeding, beweging, roken, lengte/gewicht/BMI. De aanwezigheid van iedere combinatie van risicofactoren dient op alle leeftijden aanleiding te zijn tot een intensivering van begeleiding, met de nadruk op leefstijlverandering. In de leeftijdsperiodes 4 tot 12 jaar en 12 tot 18 jaar wordt ten minste eenmaal gevraagd naar doorgemaakte ziektes sinds het laatste contact met de JGZ en naar het voorkomen van syncope/wegrakingen. Daarnaast wordt aanbevolen om te overwegen om in de leeftijdsperiode 12 tot 18 jaar de familieanamnese na te vragen, specifiek op HVZ en plotseling overlijden van 1 e en 2 e graads familieleden.

Interventies en begeleiding. Het bestaan van een vermoeden op een (aangeboren) hartafwijking kan aanleiding zijn tot veel zorg en onrust bij de ouders. Ouders hebben behoefte aan uitleg over de reden van het vermoeden, eventueel te nemen vervolgstappen en overwegingen voor deze vervolgstappen. De JGZ biedt ouders waar nodig aanvullende uitleg en informatie, opvoedadvies en opvoedondersteuning.
De advisering over de opvoeding en aanpak van het kind met een aangeboren hartafwijking is in principe hetzelfde als bij een kind zonder hartafwijking. In de anamnese tijdens een contact met ouders en/of jeugdigen wordt gevraagd naar het psychosociaal functioneren van de jeugdige. Indien er twijfel is over het psychosociale functioneren van de jeugdige kan worden overlegd met of (terug)verwezen naar de behandelend kindercardioloog.

\section{Praktijktest en randvoorwaarden voor implementatie}

De conceptrichtlijn is gedurende 4 maanden getest in de praktijk door 49 JGZ-professionals van vijf JGZorganisaties. Door middel van digitale vragenlijsten en een focusgroepinterview werden de meningen en ervaringen van de deelnemers geïnventariseerd.

De richtlijn werd zeer positief beoordeeld op inhoud en procedurele helderheid. Twee aanbevelingen gaven bezwaren, hierop zijn inhoudelijke wijzigingen aangebracht.

Om met de richtlijn te werken is leestijd en een instructie over de richtlijn nodig. Tijdens de instructie is aandacht nodig voor praktische vaardigheden met betrekking tot: het palperen van de arteriële pulsaties, het interpreteren van hartgeruisen en het herkennen van intrekkingen, cyanose en tachypnoe bij kinderen. Naast de inhoudelijke instructie/scholing wordt geadviseerd om de richtlijn te bespreken tijdens team- of discipline-overleggen.

\section{Meer informatie?}

De JGZ-Richtlijn Hartafwijkingen is ontwikkeld door TNO. De richtlijn is gefinancierd door ZonMw. Voor de volledige tekst en de ondersteunende producten, zie: www.jgzrichtlijnen.nl.

\section{Literatuur}

1. https://tinyurl.com/ya7h4fbv. Geraadpleegd: 16-11-2016.

2. Velzen Cvan, Clur S, Rijlaarsdam M, et al. Prenatal detection of congenital heart disease-results of a national screening programme. BJOG. 2015;122:1421.

3. World Health Organisation. Factsheet No 317, Cardiovascular diseases 2017. http:/ / www.who.int/mediacentre/ factsheets/fs317/en/. Geraadpleegd: 16-11-2016.

4. National Heart, Lung, and Blood Institute. Expert panel on integrated guidelines for cardiovascular health and risk reduction in children and adolescents. Pediatrics. 2011;128(Suppl5):S213-S56.

5. Deurloo JA, Heerdink N. JGZ-richtlijn Hartafwijkingen 2017. https://www.ncj.nl/richtlijnen/alle-richtlijnen/. Geraadpleegd: 16-11-2016.

J.A. Deurloo, arts Maatschappij \& Gezondheid, jeugdarts en stafarts, richtlijnontwikkelaar

N. Heerdink, arts Maatschappij en Gezondheidn.p. 